\title{
Screening of serum samples from Wegener's granulomatosis patients using antibody microarrays
}

\author{
Eric W. Olle ${ }^{1,2}$, Michael P. Deogracias ${ }^{1}$, James E. Messamore ${ }^{3}$, Shannon D. McClintock ${ }^{1}$, \\ Adam G. Barron ${ }^{1}$, Timothy D. Anderson ${ }^{2}$ and Kent J. Johnson ${ }^{1}$ \\ ${ }^{1}$ University of Michigan, Department of Pathology, Ann Arbor, MI, USA \\ ${ }^{2}$ Safety Sciences, Pfizer Global Research \& Development, Ann Arbor, MI, USA \\ ${ }^{3}$ Discovery-Biomarkers Group, Pfizer Global Research \& Development, Ann Arbor, MI, USA
}

\begin{abstract}
Wegener's Granulomatosis (WG) is an idiopathic granulomatosis autoimmune vasculitis that primarily affects small vessels and is associated with glomerulonephritis and pulmonary granulomatous vasculitis. Anti-neutrophil cytoplasmic auto-antibodies (cANCA) against proteinase-3 are used to identify WG, but ANCA titers are not present in some patients with the localized disease. The objective of this study was to develop an antibody array to help identify protein expression patterns in serum from patients with WG as compared to normals. The arrays were tested for limits of detection, background, and cross reactivity using standard proteins. The arrays were hybridized with either normal patient serum $(n=30)$ or with serum samples from a population of WG patients $(n=26)$ that were age and sex matched. Data analysis and curve fitting of the standard dilution series calculated $r^{2}$ values and determined a sensitivity of $<50 \mathrm{pg} /$ $\mathrm{mL}$ for the majority of proteins. A total of 24 proteins were assessed. Several statistically significant increases $(p<0.05)$ were seen in the expression of: angiotensin converting enzyme-I, IFN- $\gamma$, IL-8, s-ICAM-1 and s-VCAM in WG patients as compared to controls. Utilizing the antibody microarray technology has led to the identification of potential biomarkers of vascular injury in the serum of WG patients.
\end{abstract}

Keywords:

Antibody microarray / Cytokine / Vasculitis / Wegener's granulomatosis

\section{Introduction}

Vasculitis is a heterogeneous group of diseases linked by inflammation in the blood vessels. Although the exact etiology is unknown, in many cases vasculitic diseases are immune mediated, with immune complexes and delayed-

Correspondence: Dr. Kent J. Johnson, The University of Michigan School of Medicine, Department of Pathology, 1301 Catherine Rd., Ann Arbor, Ml 48109-0602, USA

E-mail: kjjkjj@umich.edu

Fax: +1-734-764-4308

Abbreviations: ACE, angiotensin I converting enzyme; CANCA, Anti-neutrophil cytoplasmic auto-antibodies; MFI, median fluorescent intensity; TBS-t, Tris-buffered saline with Tween-20; WG, Wegener's granulomatosis
Received: November 15, 2006

Revised: April 25, 2007

Accepted: April 27, 2007 type hypersensitivity reactions present in the affected vessels [1-6]. The categorization of vasculitic diseases has historically been based on size, type and location of the vessels involved. Although not all clinical presentations fit into one category it provides standard criteria for vasculitis identification [7-10]. Wegener's granulomatosis (WG), originally identified in 1936, is a form of systemic vasculitis characterized by a triad of arthritis, pulmonary granulomatosis vasculitis and glomerulonephritis [11]. Currently, WG is described as an inflammation of small to medium size vessels often leading to necrotic lesions and clinically manifesting an "ELK" triad (upper respiratory, lung and kidney) in the systemic disease [2, 4, 12, 13]. The diagnostic confirmation of vasculitis usually requires a biopsy along with clinical evaluation and evidence of anti-neutrophil cytoplasmic auto-antibodies (ANCA); pANCA (perinuclear) and cANCA (cytoplasmic) [14-18]. WG is com- 
monly associated with proteinase-3 ANCA (cANCA) autoantibodies in the majority of patients. However, in the localized disease state around $50 \%$ of the patients lack cANCA titer [19]. While cANCA titer provides a strong positive correlation to WG the elevation is not always present. Alternatively, elevations in pANCA titer are associated with WG but are also seen in a range of other autoimmune diseases $[19,20]$. Therefore, there is a need to define additional biomarkers for the accurate early detection of WG or other types of vasculitis.

Immune system markers such as cytokines, cell surface antigens and adhesion molecules have been assessed in patients with vasculitis. However, the majority of this work was done on individual analytes or from ex vivo experiments [19, 21-37]. The majority of the published studies have focused on a range of vasculitic diseases with few concentrating on WG.

Antibody arrays are a solid phase proteomic screening technology that can be designed for custom applications [3840]. There are different types of antibody microarrays such as dual label ratios [41], hapten labeled protein lysates (Biotin and DNP) [42] or micro-ELISA [38] based arrays. The antibody arrays to screen WG patient's serum were designed using a micro-ELISA based method (i.e. analyte specific capture and detection antibodies). Antibody pairs that are optimized for classical ELISA technology were used for the development of our antibody arrays. Once the array was designed and tested with standard proteins, it was hybridized with normal and WG patient's serum.

The goal of this study was to design and implement a high-throughput, semi-quantitative antibody array to evaluate the protein expression patterns in serum samples from WG patients as compared to normal controls.

\section{Materials and methods}

\subsection{Samples}

Normal human serum $(\mathrm{n}=30)$ was obtained from the Pfizer CRC clinic (Protocol \#394-0) and serum from patients diagnosed with WG $(n=26)$ in varying disease stages, was obtained from the University of Michigan (Protocol \#IRB 2000-0005). Normal human serum was defined as taking no over the counter pain medicines for one week, no steroidal anti-inflammatory drugs for at least six months, and no overt signs of illness. WG serum samples were taken from patients with high cANCA titers $(\geq 1: 160)$ and histological evidence of active disease. However, the patient population was heterogeneous (i.e. different stages and treatment of the disease) and sometimes associated with other auto-immune diseases. The serum samples were age and sex matched. Vasculitis affected patients had a mean age of $53 \pm 22$ with $45 \%$ females, whereas the normal patient population had a mean age of $51 \pm 23$ with $48 \%$ females.

\subsection{Antibody array development and manufacture}

Antibody microarrays were generated using commercially available antibody pairs and standard proteins (R\&D Systems, Minneapolis, MN). Antibody arrays were spotted using a Piezorray $^{\text {TM }}$ (PerkinElmer, Boston, MA) following standard protocols targeting to 16 specific sub-arrays designed to work with the ProPlate ${ }^{\mathrm{TM}}$ system (Grace Bio-labs/Molecular Probes, Eugene, OR). Capture antibodies were diluted in spotting buffer (100 mM $\mathrm{NaHPO}_{4}$ (pH 9.0), $50 \mathrm{mM} \mathrm{NaCl}, 50 \mathrm{mM}$ Trehalose and 5\% glycerol (Sigma, St. Louis, MO) and spotted onto EpoxyES microarray slides (Erie Scientific, Portsmouth, NH) [39]. As a control for non-specific binding, isotype control and non-specific IgG antibodies were spotted on the array. In initial studies the capture antibody was diluted at a range of concentrations $(25 \mu \mathrm{g} / \mathrm{mL}$ to $500 \mu \mathrm{g} / \mathrm{mL})$ that were tested with mixed standards in phosphate buffered saline, 5\% BSAwith 0.01\% Tween-20 (Gibco/Invitrogen, Carlsbad, CA) (range: 1.22 to $5000 \mathrm{pg} / \mathrm{mL}$ ) with the detection antibody diluted 1:200. Antibody microarrays were hybridized, scanned and quantified as outlined below. Optimal concentration of the secondary antibody was determined by diluting and applying dilution antibodies (range: 1:200 to $1: 1000$ ) on slides with the capture antibody spotted that were spotted at a range of concentrations with a dilution series of the standards (range 24 to $1000 \mu \mathrm{g} / \mathrm{mL}$ ). The standards with an $r^{2}$ of $>0.95$ were utilized for quantization. Antibody microarrays were hybridized, scanned and quantified as outlined below. An optimized antibody pair was defined as providing a median fluorescent intensity (MFI) that responded in a dose dependent-manner and did not saturate the MFI signal until the higher concentrations. Once an optimal dilution was determined for both capture and detection antibodies, standards were spiked into normal human serum at $1000 \mathrm{pg} / \mathrm{mL}$ to determine percent recovery (goal: 85-115\%). Standards were spiked individually into standard diluent at $1000 \mathrm{pg} / \mathrm{mL}$ to determine cross reactivity and any antibody that showed non-specific cross-reactivity was excluded. The standards were mixed together for the analysis of the patient samples as reported previously [38]. Antibody microarrays were hybridized, scanned and quantified as outlined below. The antibody pairs were optimized for overall performance instead of skewing to a lower limit that would cause an early signal saturation and decrease overall linear range. The lowest limit of detection was defined as the first standard significantly different than the 0 point. Antibody pairs that had a high lower limit of detection and did not generate a good standard curve or low signal but did not cross-react were considered non-quantifiable and were used solely to determine relative expression based on MFI.

Normal and WG (vasculitis) diagnosed, human serum was profiled on the antibody microarray. Antibody microarrays were printed for the ProPlate ${ }^{\mathrm{TM}}$ system with the capture antibody spotted in triplicate. Standards were prepared and the unknowns were diluted appropriately. Samples were repeated in completely independent, randomized experi- 
ments to determine reproducibility. Antibody microarrays were hybridized, scanned and quantified as outlined in Section 2.3..

\subsection{Antibody microarray hybridization}

Standards were diluted into Tris-buffered saline $\mathrm{pH} 7.4$ (Rockland Inc, Gilbertsville PA) with 0.1\% Tween-20 and 5\% BSA (Sigma, St. Louis, MO). Serum samples were diluted four-fold in Tris-buffered saline with Tween-20 (TBS-t). The EpoxyES coated-slides were placed in the ProPlate ${ }^{\mathrm{TM}}$ system and washed twice with TBS-t and blocked for $30 \mathrm{~min}$ at room temperature with $0.5 \%$ dry milk, $0.5 \%$ BSA (Sigma) in TBS-t on a rotating platform. The block was removed and the standards and diluted serum samples were placed on the antibody microarray (100 $\mu \mathrm{L}$ per well) in duplicate. The arrays were covered and placed on a rotating platform at $4^{\circ} \mathrm{C}$ overnight. Arrays were washed at least three times with TBS$t$ and detection antibodies diluted in block were incubated for $2 \mathrm{~h}$ on a rotating platform at room temperature. Arrays were washed as above and detection antibody was hybridized with Alexa Fluor 647-strepavidin (Molecular Probes) diluted 1:2500 in block and incubated at room temperature on a rotating platform in the dark. Arrays were washed as above, removed from the ProPlate ${ }^{\mathrm{TM}}$ system, dipped in TBS, dipped in double distilled $\mathrm{H}_{2} \mathrm{O}$ and dried using compressed air. Slides were stored in the dark at room temperature until they could be scanned.

\subsection{Antibody microarray scanning, quantification and analysis}

Slides were scanned on an Axon 4000B using GenePix 6.0 (Axon Instruments/Molecular Devices, Sunnyvale, CA). Single laser was used and laser intensity was adjusted so the highest standards were not saturated and the same intensity was used for all slides processed during the same experiment. GenePix 6.0 (Axon Instrument/Molecular Devices) and the antibody array gal file were used to quantify the antibody arrays. MFI data minus the background was imported into PrismGraph 4.0 (GraphPad Software, Inc. San Diego, CA). Standard curve and unknowns were calculated using the curve fitting function and quantifiable analytes were plotted based on concentration. Samples that were not within the standard linear range or had a high non-specific background in the isotype antibody controls were excluded from analysis. Normal and vasculitis patient serum were compared using a two-tailed t-test and considered significant if $p<0.05$.

\section{Results}

\subsection{Antibody microarray development}

An overall view of a scanned ProPlate antibody microarray used for titration with standard dilution series is shown in
Fig. 1A. Initial titration of the amount of antibody spotted showed that the concentration of the capture antibody can affect the standard curve as illustrated with the TNF- $\alpha$ antibody (Fig. 1B). The optimal amount of capture antibody spotted was independent of the host animal (not shown). Antibody pair performance was relative to the capture and detection antibodies. Antibody (capture or detection) concentrations that were too high saturated the curve early and usually had a high background, whereas concentrations too low negatively impacted the limit of detection.

Titration of the detection antibodies as illustrated with the IL-5 antibody (Fig. 1C) illustrates that both the capture and secondary antibody concentrations could be determined concurrently. This allows for the optimization of both capture and detection and to quickly determine if there are quantifiable differences. No significant changes were made when the capture and detection antibodies were titrated individually. An optimized antibody pair had: (i) large linear range of detection, (ii) low limit of detection (i.e. $<50 \mathrm{pg} / \mathrm{mL}$ ), (iii) no cross-reactivity, (iv) percent recovery between $85-115 \%$ and (v) a low background (usually $<1000 \mathrm{MFI}$ ). No cross reactivity was seen using $1000 \mathrm{pg} / \mathrm{mL}$ of standard proteins individually spiked into TBS-t with 5\% BSA. The list of 24 proteins for which optimized antibody pairs could be identified is shown in Table 1. Table 1 also lists the detection range, percent recovery, and curve fit $\left(r^{2}\right)$ for each of the optimized antibody pairs.

A $\log$ transformation of the protein concentration and curve fitting of the standards showed that the representative set of the standards had an $r^{2}>0.95$ (Fig. 2). This shows the $\log$ of the concentration (x-axis) with the MFI minus background. Proteins with an $r^{2}<0.95$ were used to determine relative (non-quantitative) expression based on the MFI. Four proteins that did not perform according to our a priori determined quantitative standards, which were C5a, CD62E, CD62I and CD62P (Table 1).

\subsection{Analysis of patient samples}

Vasculitis patient and normal serum samples were analyzed alongside standard protein dilution series to allow for quantification of the samples. Each patient sample was replicated three times per plate and repeated an additional 3-4 times with different plates. Analysis of the standard curves showed that the majority of standards performed as expected from the initial experiments described above. The standards showed no statistical difference between the titration experiments and the experimental ones. Analysis of patient samples was completed by back-calculating the concentration base on the standard curve and multiplying by the dilution factor (four-fold). If a sample reacted with the non-specific IgG control antibodies, the sample was excluded. This accounted for $10 \%$ of the normal and $11 \%$ of the WG samples. Non-specific reactivity showed no connection between well location or print lot number and therefore was probably due to the samples. Individual protein levels that were outside the standard curve were excluded, however in our hands 


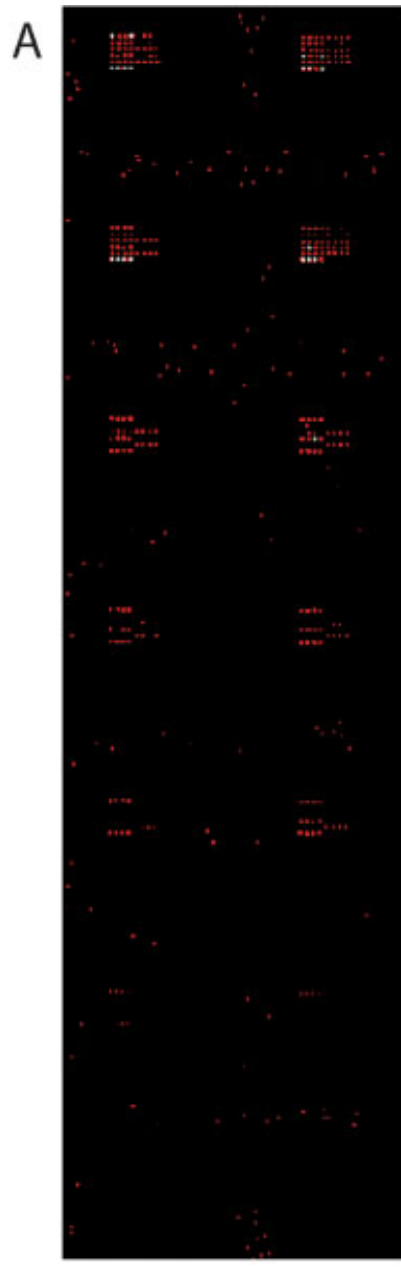

\section{B
Effect of Capture Antibody Titration on TNF- $\alpha$

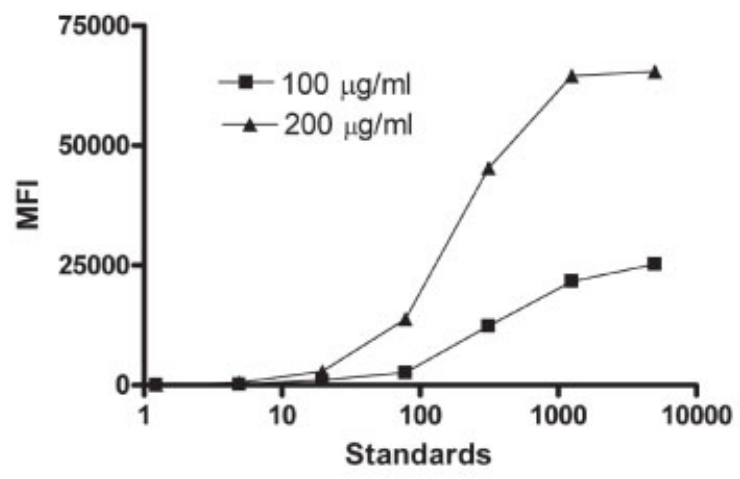

C

\section{Effect of Secondary Antibody Dilution on IL-5}

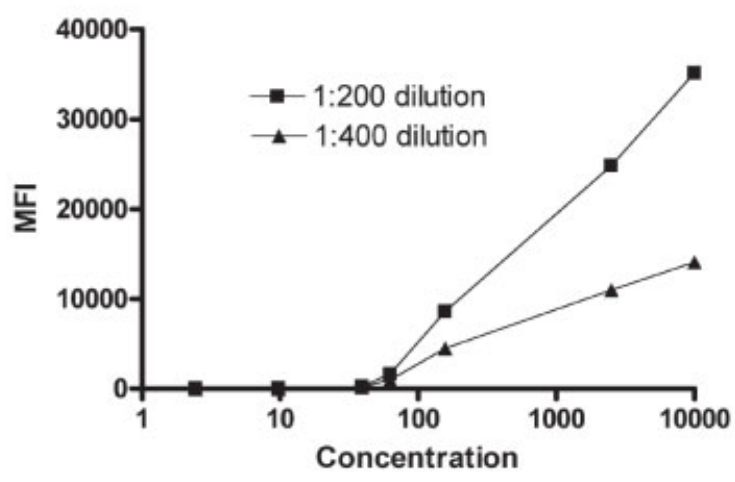

Figure 1. Optimization of capture and detection antibody concentrations. A representative standard curve antibody array slide is shown in (A). A representative effect of capture antibody concentration on MFI is shown using TNF- $\alpha$ and concentration effects was on MFI determined for all capture antibodies (B). The effect of the secondary (detection) antibody dilution on MFI is shown in (C) with IL-5 being the representative protein analyte. with the four-fold dilution this rarely occurred. Expression levels of the specific proteins in most cases followed expected expression patterns compared to what has been previously reported in the literature and the majority of the normal samples fell within expected expression levels (Fig. 3). The array showed a high degree of reproducibility with $<5 \%$ coefficient of variation per plate and $<10 \%$ between ProPlate runs. Figure 3 shows the quantifiable serum proteins as a whisker plot to show the total variation, $25^{\text {th }}, 50^{\text {th }}$, and $75^{\text {th }}$ percentiles. The graphs are separated into three parts to aid in readability. The patient population with vasculitis showed a significantly $(p<0.05)$ increased amount of: angiotensin I converting enzyme (ACE), IFN- $\gamma$, IL-8, s-ICAM and s-VCAM in the serum as compared to the controls. The quantified values for these five proteins are shown in Table 2 along with the standard error of the mean and fold difference. The fold differences between the normal and the WG patients ranged between 1.8-fold for the ACE expression to 12.1-fold for IL-8. Additionally, there were non-significant increases seen in the expression of: IL-1 $\beta$, IL-2, IL-10, IL-6 MIP-1 $\beta$, TGF- $\beta$, TNF$\alpha$, VEGF and E-selectin in the vasculitis patients as com- pared to controls (Fig. 3). Not all proteins were up regulated and IL-4 and IL-5 showed non-significant decreases in the WG patient group as compared to the healthy controls. Figure 4 shows a whisker plot of the non-quantifiable serum proteins evaluated with MFI plotted instead of concentration in $\mathrm{pg} / \mathrm{mL}$. No significant differences were seen in the non-quantitative group. However, a possible trend of increased C5a was seen in WG but was not statistically significant.

\section{Discussion}

This study is the first to utilize antibody microarrays to screen serum samples from patients with WG which allows for the rapid analysis of multiple proteins in the serum in a high-throughput manner without making any $a$ priori assumptions about which proteins to assess. Using this technology we have found that the levels of several proteins in the serum are significantly increased in patients with WG as compared to controls including: ACE, IFN- $\gamma$, IL-8, s-ICAM and s-VCAM. Thus, it appears as if 
Table 1. Summary of the antibody pair performance.

\begin{tabular}{|c|c|c|c|c|}
\hline Proteins & Catalog number & Range $(\mathrm{pg} / \mathrm{mL})$ & Percent recovery & Curve fit $r^{2}$ \\
\hline ACE & DY 929 & $<2.4-10000$ & 93.1 & 0.979 \\
\hline $\mathrm{C} 5 \mathrm{a}$ & AF/BAF 2037 & $>1667$ & ND & $<0.95$ \\
\hline E-Selectin/CD62E & DY 724 & $>1667$ & ND & $<0.95$ \\
\hline IFN- $\gamma$ & DY 285 & $6.86-5000$ & 89.4 & 0.981 \\
\hline $\mathrm{IL}-1 \alpha$ & DY 200 & $2.4-10000$ & 107.9 & 0.974 \\
\hline IL-1 $\beta$ & DY 201 & $<1.2-5000$ & 95.2 & 0.971 \\
\hline IL-2 & DY 202 & $<1.2-5000$ & 86.8 & 0.961 \\
\hline IL-4 & DY 204 & $6.86-5000$ & 87.7 & 0.959 \\
\hline IL-5 & DY 205 & $1.2-5000$ & 102.4 & 0.953 \\
\hline IL-6 & DY 206 & $<1.2-5000$ & 95.1 & 0.951 \\
\hline CXCL8/IL-8 & DY 208 & $2.4-5000$ & 96.1 & 0.961 \\
\hline IL-10 & DY 217B & $6.86-5000$ & 87.3 & 0.973 \\
\hline IL-13 & DY 213 & $1.2-5000$ & 86.4 & 0.964 \\
\hline Leptin & DY 398 & $61.7-10000$ & 90.9 & 0.953 \\
\hline L-Selectin/CD62L & DY 728 & $>555$ & 86.2 & 0.933 \\
\hline CCL3/MIP-1 $\alpha$ & DY 270 & $1.2-5000$ & 89.5 & 0.978 \\
\hline CCL4/MIP-1 $\beta$ & DY 271 & $1.2-5000$ & 93.6 & 0.99 \\
\hline $\mathrm{P}-$ Selectin/CD62P & DY 137 & $>1667$ & ND & $<0.95$ \\
\hline s-ICAM & DY 720 & $61.7-5000$ & 91.9 & 0.965 \\
\hline TGF- $\beta$ & DY 239 & $1.2-5000$ & 101.7 & 0.99 \\
\hline TNF- $\alpha$ & DY 210 & $6.86-5000$ & 95.2 & 0.99 \\
\hline s-VCAM & DY 809 & $6.86-5000$ & 89.4 & 0.976 \\
\hline VEGF & DY 293B & $6.86-5000$ & 96.6 & 0.989 \\
\hline XIAP & DY 822 & $6.86-5000$ & 85.7 & 0.975 \\
\hline
\end{tabular}

Antibody pairs were tested in either phosphate buffered saline, TBS-t with $5 \%$ BSA or spiked into normal human serum. Range was determined as the lowest level of detection that was greater than two-SDs from the 0 standard and highest limit of detection was determined as the last standard that was not saturated and with a MFI greater than the previous standard. Percent recovery was determined by spiking the standard proteins into both TBS-t with $5 \%$ BSA and normal human serum at $1000 \mathrm{pg} / \mathrm{mL}$ normal human serum percent recovery is shown. Antibody pairs with limit of detection $>1000 \mathrm{pg} / \mathrm{mL}$ did not have the percent recovery determined (ND). Curve fit was determined on analytes using a log transform of the standard dilution in TBS-t with 5\% BSA. ND = not determined. All data is the mean of at least four independent experiments.

the use of the antibody array technology provides an ideal platform for which to assess protein levels in biofluids in these patients and may differentiate this complex disease process.

Antibody microarrays are a customizable high-throughput screening technology that can be applied to a range of samples. This technology can be easily applied to existing matched antibody pairs and with minimal difficulty applied to pairs of unmatched pairs antibodies. The majority of the matched antibody sets performed quantitatively and had a low background, had low limits of detection, and performed similarly to classical single ELISA's with no significant differences in range of detections. One exception was s-VCAM that had a background 50 to 100 -fold greater than the others, however this antibody still performed well in all other tests and was considered quantitative. Other antibodies such as: C5a, CD62E. CD62L and CD62P did not perform up to our acceptance criteria. This was expected from the C5a antibody pair since the capture and detection antibodies were the same but the detection antibody was biotinylated. The C5a antibodies used in the antibody microarray per- formed similar to classical ELISA in range of detection. The CD62 family performed better at the higher concentrations but lacked the lower limit of detection seen with the other analytes and did not meet our lower limit of detection acceptance criteria.

The application of the custom antibody microarray was straightforward once the optimal antibody concentration for the array was developed. A mixture of standard proteins were diluted to generate an eight-point standard curve and hybridized in duplicate along side the serum samples similar to classical ELISA protocols. The MFI was determined and samples non-specifically cross-reacting with the background controls were excluded. While uncommon, in 10 to $11 \%$ of the samples from both groups had a high non-specific background and cross-reactivity with the isotype control antibodies was seen in both groups. The non-specific background may be decreased by using additional blocking, increasing the dilution, or may be indicative of antibodies against animal immunoglobulin. As expected, some of the serum proteins were outside the limit of detection on the antibody pairs in a selected sample but this did not affect the 


\section{Calculation of Standard Curves}

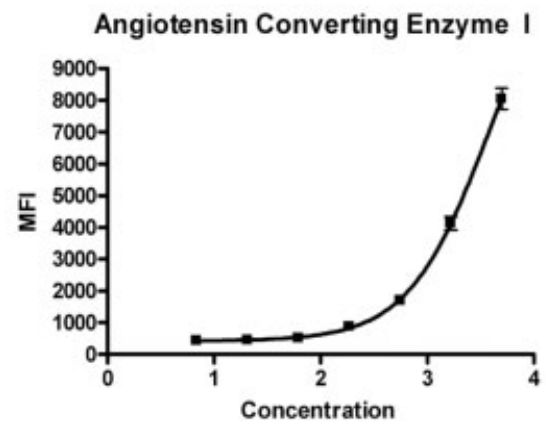

IL-8

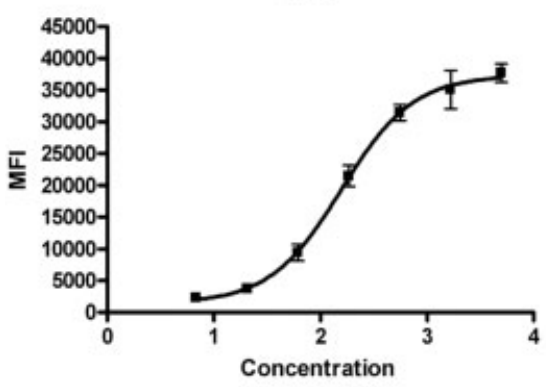

VCAM

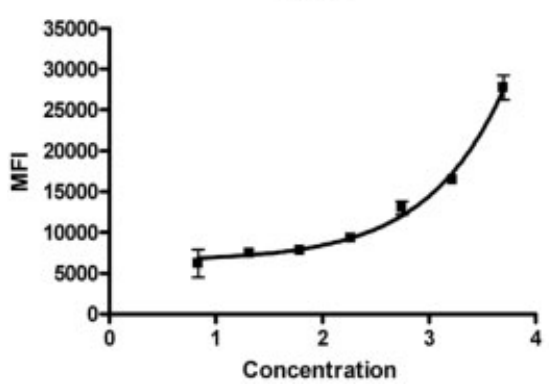

Interferon- $\gamma$

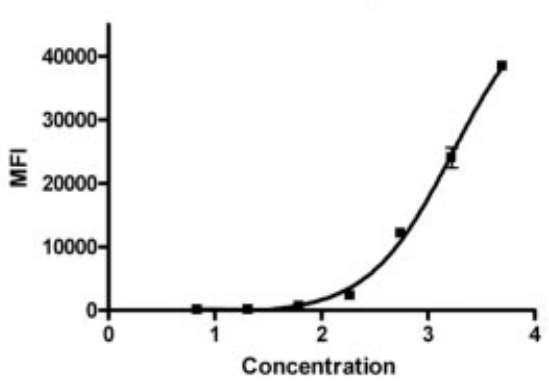

S-ICAM

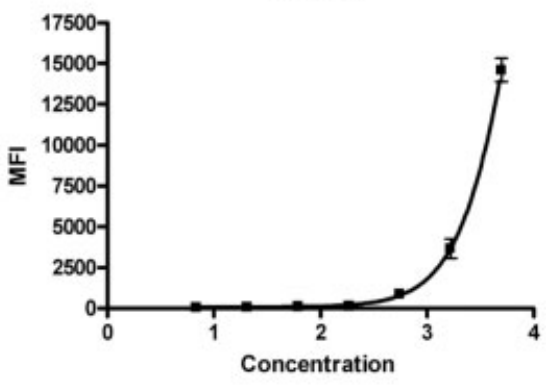

IL-6

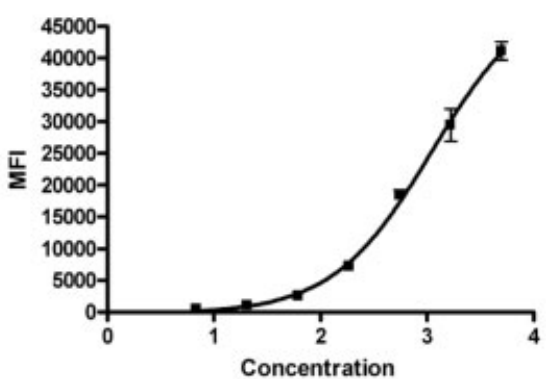

Figure 2. Calculation of standard curves. Representative standard curves shown are using protein standard curve (including 0 ) diluted in TBS-t with $5 \%$ BSA. Mean MFI was log transformed and 4-parameter logistic calculation was used to curve fit (lines). Curve fit data was generated from representative standard proteins is shown curve fit analysis with a linear $y$ and logarithmic $x$-axis. Curve fit data was generated for all protein analytes. Shown is the mean of four independent experiments with error bars indicating \pm SEM. majority of samples or proteins. Knowing the expected concentration range and designing the antibody microarray antibody pairs is one aspect that should be accounted for in the initial design. The antibody microarray performed well when used for patient samples and was quantifiable for most (21 out of 24) of proteins tested.

The proteins ACE, IFN- $\gamma$, IL- 8 , s-ICAM and s-VCAM show statistical differences between the normal and WG patients $(p<0.05)$. In fact these proteins are markedly increased in the serum of WG patients as compared to controls with fold change increases ranging from 1.8-12.1. These fold increases have also been found to be significant in other studies measuring serum protein cytokine levels in other diseases [43]. Several other inflammatory related proteins are also increased in the patients with WG but they did not achieve statistical significance. This indicates the need for a serial, controlled prospective study using antibody microarrays with vasculitic patients. Interestingly, increased ACE expression was not observed in patients with positive pANCA titers that had diseases such as systemic lupus erythematosus (SLE) or inflammatory bowel disease while the WG may have been in possible remission due to treatment [21].

Most studies to date have utilized isolated peripheral blood mononuclear cells in WG patients to assess their production of Th1 and Th2 cytokines. These studies have found evidence of a primarily Th1 systemic response in these patients with primarily CD4 + T cells producing IFN- $\gamma$, IL-12 and TNF- $\alpha$. $[9,25]$. In terms of assessing cytokine levels in plasma or serum from WG patients using ELISA based systems there are a limited number of preliminary studies that 

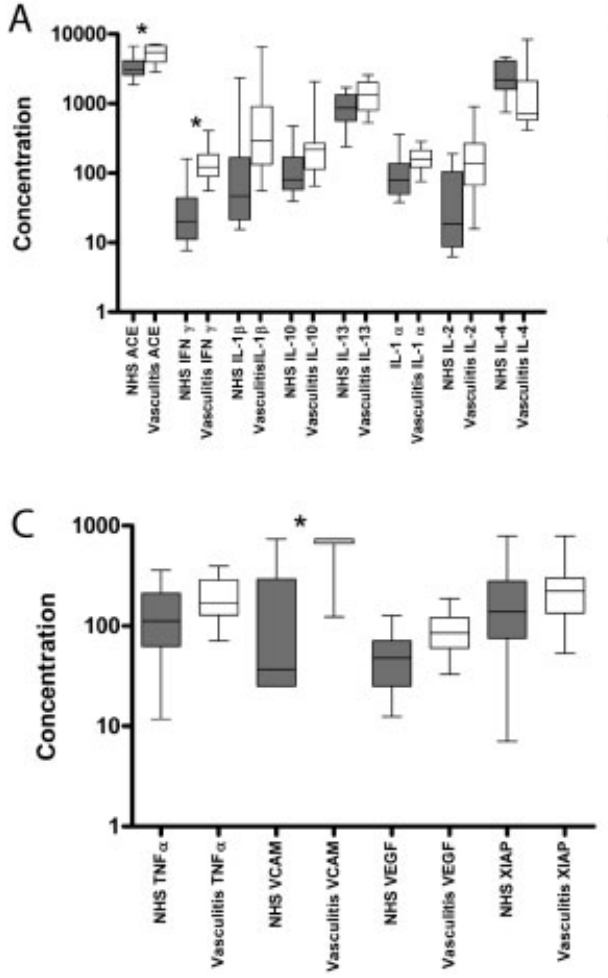

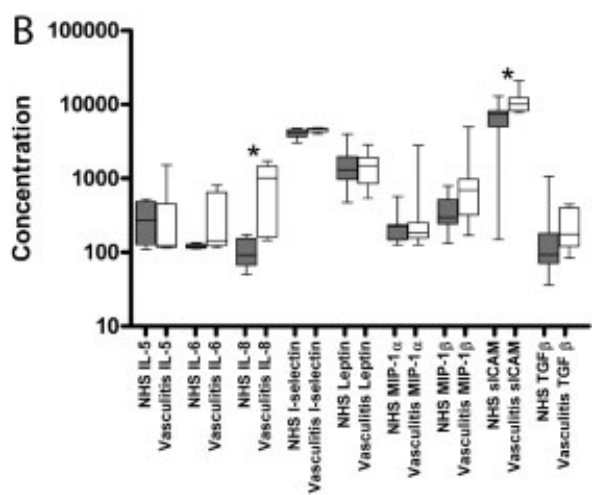

Figure 3. Analysis of quantitative analytes. Normal human serum and WG (vasculitis) serum was analyzed on the antibody microarray. Concentration was calculated based on MFI and curve fit equation generated by the protein standards. The mean of duplicate wells with three replicate spots per well was plotted on a whisker plot showing the total variability, $25^{\text {th }}, 50^{\text {th }}$ and $75^{\text {th }}$ percentiles with concentration ( $y$-axis) plotted in a log scale to allow for plotting of a range of different analytes due to difference in concentration. Statistical differences were determined using a two-tailed t-test and considered significant if $p<0.05(*)$. Proteins analyzed were broken into three different graphs ( $A, B$, and $C$ ).
Table 2. Quantified values of statistically different analytes

\begin{tabular}{lccl}
\hline Proteins & Normal $(\mathrm{pg} / \mathrm{mL})$ & $\begin{array}{l}\text { Wegener's } \\
\text { granulomatosis } \\
(\mathrm{pg} / \mathrm{mL})\end{array}$ & $\begin{array}{l}\text { Fold } \\
\text { change }\end{array}$ \\
\hline ACE-I & $3290.1( \pm 214.3)$ & $5927.1( \pm 283.0)$ & +1.8 \\
IFN- $\gamma$ & $23.4( \pm 3.4)$ & $151.4( \pm 19.5)$ & +6.5 \\
IL-8 & $107.3( \pm 9.0)$ & $1294.0( \pm 55.3)$ & +12.1 \\
S-ICAM & $6195.2( \pm 533.7)$ & $12679.4( \pm 870.7)$ & +2 \\
s-VCAM & $120.7( \pm 26.5)$ & $674.3( \pm 28.8)$ & +5.6 \\
\hline
\end{tabular}

Five proteins in serum were found to have statistically different expression based on a two-tailed t-test $(p<0.05)$. The quantified values along with standard error of the mean (in parentheses) are shown and allow for comparison of normal and WG serum samples. The fold change shows the difference between the normal and affected patients analyte expression with positive $(+)$ indicating an increase in WG patients serum.

assessed a relatively small number of cytokines from a small cohort of WG patients. Two studies showed elevations in IL6 , IL- 8 and IL-10 and TNF- $\alpha$ proteins $[44,45]$. In another study where only three patients were assessed increased circulating levels of IFN- $\alpha$ and IL- 2 could be detected whereas IFN- $\gamma$ and TNF- $\alpha$ levels were not elevated [37]. In terms of measuring soluble adhesion molecules only one study to date has looked at this and found that WG patients had elevations in s-ICAM but not s-VCAM [28]. Thus the studies to date have been largely preliminary with different results for some of the same proteins.

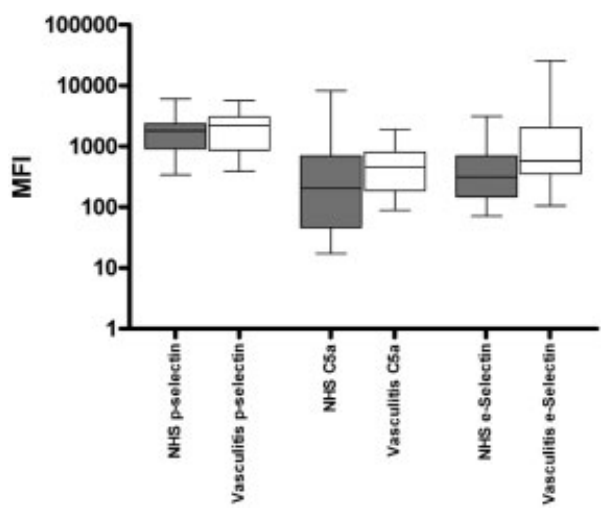

Figure 4. Analysis of the non-quantitative analytes. Three analytes were not quantitative due to poor performance on the standard curve analysis. MFI was used to determine if there are differences in expression. The mean of duplicate wells with three replicate spots per well was plotted on a whisker plot showing the total variability, $25^{\text {th }}, 50^{\text {th }}$ and $75^{\text {th }}$ percentiles. Statistical analysis showed no significant differences between the normal and the WG (vasculitis) patient serum.

The increased expression of ACE in the WG samples or other types of vasculitis has not been reported to date and is potentially of great interest since ACE is expressed in high levels by endothelial cells. ACE inhibitors have been implicated in vasculitic lesions and one case report showed a link between ACE and granulomatosis disease of unknown etiology [46-48]. Increased expression of ACE expression in the WG patients is a more than likely a reaction to the disease 
state and not gene polymorphisms [49]. A possible reason for increased ACE levels could be steroidal anti-inflammatory treatment but this is unlikely since prednisolone has been shown to decrease ACE in asthmatic patients [50]. Additionally, the angiotensin system has been implicated in endothelial cell damage, vascular inflammation and may be involved in end organ damage [51]. The exact role of ACE in the development of vasculitis remains to be determined.

The expression of TGF- $\beta 1$ has been shown to be elevated in systemic vasculitis including WG [34]. The antibody microarray detected similar amounts of TGF- $\beta$ as was reported, but in our study there were no statistical differences between the normal and the WG samples. Possible explanations include variability in the normal and vasculitis samples and the fact that the antibody array measures total TGF- $\beta$ instead of active. Additionally, the expression of several other cytokines implicated in vasculitis such as IL-1 $\beta$, IL-2, IL-10, IL-6 MIP-1 $\beta$, TGF- $\beta$, TNF- $\alpha$, VEGF and e-Selectin showed no differences between controls and vasculitis patients. Interestingly, the normal population showed a wide range of expression in a few proteins probably due to undisclosed sub-clinical illness or reflects the variability of expression. However, the mean expression of the proteins in the normal human serum group was within the expected normal range. The expression of several cytokines have been implicated in vasculitis and remain to be investigated with a prospective serial study using high-throughput proteomic technology [50-54].

In summary, screening of WG patient sera with an optimized antibody array revealed significant upregulation of ACE, IFN-y, IL-8, s-ICAM and s-VCAM as compared to a control population. The increased expression on many of these proteins such as ACE and s-VCAM in these patients has not been previously described and suggests that these proteins may be possible selective markers of vascular injury. The development, implementation and screening of patient samples using antibody microarrays is a straightforward process and further studies will use this technology to determine if other types of vasculitis also have similar patterns of protein expression and whether this pattern of protein expression is specific for WG.

The authors would like to thank: Dr. Tiffany Lasky, Benjamin Genisio and John Neufeld for their interesting discussions and reading of the manuscript.

\section{References}

[1] Falk, R. J., Jennette, J. C., J. Nephrol. 2004, 17 (Suppl 8), S3S9.

[2] Crowson, A. N., Mihm, M. C., Jr., Magro, C. M., J. Cutan. Pathol. 2003, 30, 161-173.

[3] Langford, C. A., J. Allergy Clin. Immunol. 2003, 111, S602S612.
[4] Gonzalez-Gay, M. A., Garcia-Porrua, C., Best Pract. Res. Clin. Rheumatol. 2002, 16, 833-845.

[5] Abdou, N. I., Clin. Allergy Immunol. 2002, 16, 435-447.

[6] Mohan, N., Kerr, G. S., Best Pract. Res. Clin. Rheumatol. 2001, 15, 203-223.

[7] Jennette, J. C., Falk, R. J., Andrassy, K., Bacon, P. A. et al., Arthritis Rheum. 1994, 37, 187-192.

[8] Leavitt, R. Y., Fauci, A. S., Bloch, D. A., Michel, B. A. et al., Arthritis Rheum. 1990, 33, 1101-1107.

[9] Luqmani, R. A., Robinson, H., Best Pract. Res. Clin. Rheumatol. 2001, 15, 187-202.

[10] Saleh, A., Stone, J. H., Best Pract. Res. Clin. Rheumatol. 2005, 19, 209-221.

[11] Wegener, F., Verh. Dtsch. Path. Ges. 1936, 29, 202-210.

[12] Yi, E. S., Colby, T. V., Semin. Diagn. Pathol. 2001, 18, 34-46.

[13] DeRemee, R. A., Curr. Opin. Pulm. Med. 1995, 1, 363-367.

[14] Harper, L., Williams, J. M., Savage, C. O., Biochem. Soc. Trans. 2004, 32, 502-506.

[15] Borgmann, S., Haubitz, M., Clin. Exp. Rheumatol. 2004, 22, S79-S86.

[16] Schultz, D. R., Diego, J. M., Semin. Arthritis Rheum. 2000, 29, 267-285.

[17] Montecucco, C., Monaldi Arch. Chest Dis. 1994, 49, 323-326.

[18] Gross, W. L., Csernok, E., Flesch, B. K., J. Autoimmun. 1993, $6,171-184$

[19] Lamprecht, P., Gross, W. L., Herz 2004, 29, 47-56.

[20] Schnabel, A., Hauschild, S., Gross, W. L., Int. Arch. Allergy Immunol. 1996, 109, 201-206.

[21] Torheim, E. A., Yndestad, A., Bjerkeli, V., Halvorsen, B. et al., Clin. Exp. Immunol. 2005, 140, 376-383.

[22] Spriewald, B. M., Witzke, O., Wassmuth, R., Wenzel, R. R. et al., Ann. Rheum. Dis. 2005, 64, 457-461.

[23] Csernok, E., Autoimmun. Rev. 2003, 2, 158-164.

[24] Borgmann, S., Endisch, G., Hacker, U. T., Song, B. S., Fricke, H., Am. J. Kidney Dis. 2003, 41, 933-942.

[25] Lamprecht, P., Kumanovics, G., Mueller, A., Csernok, E. et al., Clin. Exp. Immunol. 2002, 128, 181-186.

[26] Jonasdottir, O., Petersen, J., Bendtzen, K., APMIS 2001, 109, 781-786.

[27] Zhou, Y., Giscombe, R., Huang, D., Lefvert, A. K., J. Rheumatol. 2002, 29, 317-320.

[28] Ohta, N., Fukase, S., Aoyagi, M., Auris Nasus Larynx 2001, 28, 311-314.

[29] Coulomb-L'Hermine, A., Capron, F., Zou, W., Piard, F. et al., Hum. Pathol. 2001, 32, 320-326.

[30] Kiene, M., Csernok, E., Muller, A., Metzler, C. et al., Arthritis Rheum. 2001, 44, 469-473.

[31] Mayet, W., Schwarting, A., Barreiros, A. P., Schlaak, J., Neurath, M., Eur. J. Clin. Invest. 1999, 29, 973-979.

[32] Muller Kobold, A. C., Kallenberg, C. G., Tervaert, J. W., Ann. Rheum. Dis. 1999, 58, 237-245.

[33] Brooks, C. J., King, W. J., Radford, D. J., Adu, D. et al., Clin. Exp. Immunol. 1996, 106, 273-279.

[34] Csernok, E., Szymkowiak, C. H., Mistry, N., Daha, M. R. et al., Clin. Exp. Immunol. 1996, 105, 104-111.

[35] Noronha, I. L., Kruger, C., Andrassy, K., Ritz, E., Waldherr, R., Kidney Int. 1993, 43, 682-692. 
[36] Deguchi, Y., Shibata, N., Kishimoto, S., Clin. Exp. Immunol. 1990, 81, 311-314.

[37] Grau, G. E., Roux-Lombard, P., Gysler, C., Lambert, C. et al., Immunology 1989, 68, 196-198.

[38] Knight, P. R., Sreekumar, A., Siddiqui, J., Laxman, B. et al., Shock 2004, 21, 26-30.

[39] Olle, E. W., Messamore, J., Deogracias, M. P., McClintock, S. D. et al., Exp. Mol. Pathol. 2005, 79, 206-209.

[40] Seong, S. Y., Choi, C. Y., Proteomics 2003, 3, 2176-2189.

[41] Haab, B. B., Dunham, M. J., Brown, P. O., Genome Biol. 2001, 2, RESEARCHOOO4.

[42] Olle, E. W., Sreekumar, A., Warner, R. L., McClintock, S. D. et al., Mol. Cell. Proteomics 2005, 4, 1664-1672.

[43] Kaminska, J., Nowacki, M. P., Kowalska, M., Rysinska, A. et al., Tumour Biol. 2005, 26, 186-194.

[44] Ohlsson, S., Wieslander, J., Segelmark, M., Mediators Inflamm. 2004, 13, 275-283.

[45] Schonermarck, U., Csernok, E., Trabandt, A., Hansen, H., Gross, W. L., Clin. Exp. Rheumatol. 2000, 18, 457-463.
[46] Carrington, P. R., Sanusi, I. D., Zahradka, S., Winder, P. R., Cutis 1993, 51, 121-123.

[47] Katz, P., Fauci, A. S., Yeager, H., Jr.,Reen, B. M., Ann. Intern. Med. 1981, 94, 359-360.

[48] Wang, A. Y., Lai, K. N., Li, P. K., Leung, C. B., Lui, S. F., Ren. Fail. 1996, 18, 293-298.

[49] Murakozy, G., Gaede, K. I., Ruprecht, B., Gutzeit, O. et al., J. Mol. Med. 2001, 79, 665-670.

[50] Roulston, J. E., O'Malley, G. I., Douglas, J. G., Thorax 1984, $39,356-360$.

[51] Muller, D. N., Fiebeler, A., Park, J. K., Dechend, R., Luft, F. C., Clin. Nephrol. 2003, 60 (Suppl 1), S2-S12.

[52] Huang, D., Zhou, Y., Hoffman, G. S., Best Pract. Res. Clin. Rheumatol. 2001, 15, 239-258.

[53] Levine, S. M., Stone, J. H., Best Pract. Res. Clin. Rheumatol. 2001, 15, 315-333

[54] Vila, E., Salaices, M., Am. J. Physiol. Heart Circ. Physiol. 2005, 288, H1016-H1021. 